Fecha de recepción: marzo 2020 Fecha de aceptación: abril 2020 Versión final: mayo 2020

\section{Artesanas migrantes, saberes ancestrales y una experiencia en el Museo de Arte Popular José Hernández (MAP)}

Margarita Barretto ${ }^{(1)}$ y Mirta Bialogorski ${ }^{(2)}$

\begin{abstract}
Resumen: A partir de un proyecto llevado a cabo en el Museo de Arte Popular José Hernández (GCBA) con artesanas textiles de Argentina y Paraguay, nos propusimos reflexionar acerca de conceptos tales como arte popular, saberes ancestrales, memoria, migración, identidad e hibridación cultural, a la luz de sus vivencias como tejedoras migrantes en la ciudad de Buenos Aires. Se definen los conceptos mencionados, se hace referencia al camino transitado por algunas de las entrevistadas y al significado que otorgan al acto de tejer. Ellas son portadoras de conocimientos tradicionales, así como de una cultura híbrida, tanto en lo que producen como en la forma de hacerlo y en el apego a su terruño al que vuelven frecuentemente. Entrando y saliendo de la modernidad, se integran en la ciudad mediante su saber heredado de sus mayores. El estar en dos mundos va reconfigurando sus identidades y da una impronta a sus creaciones.
\end{abstract}

Palabras clave: artesanas textiles - culturas híbridas - migración - arte popular - identidad - memoria.

[Resúmenes en inglés y portugués en las páginas 166-167]

(1) Margarita Barretto es Doctora en Educación con post doctorado en Antropología Social. Tiene curso de grado y especialización en Museología; curso de grado en Turismo y especialización en Metodología de la Enseñanza. Profesora visitante en la Universidad Federal de Santa Catarina e investigadora nivel $1 \mathrm{C}$ del CNPq (Consejo Nacional de Investigación) de Brasil. Realiza un estudio comparativo del uso turístico del patrimonio, en las misiones jesuíticas de Argentina (Misiones), Brasil (Rio Grande del Sur) y Uruguay (Colonia del Sacramento). Actúa también como docente invitada en la carrera de posgrado en Gestión del Patrimonio Cultural de la FADU-Universidad de Buenos Aires. Con más de 37 años de carrera docente, es autora de veinte libros, capítulos de libros y obras colectivas, en Argentina, Brasil y España, países donde también ha publicado un centenar de artículos científicos y es miembro del consejo editorial de revistas científicas. Ha dirigido treinta y seis tesis de maestría y doctorado y participa intensivamente de congresos y similares donde suele ser invitada como conferencista.

(2) Mirta Bialogorski es Doctora en Antropología (Universidad de Buenos Aires). Licenciada en Ciencias Antropológicas, Facultad de Filosofía y Letras (UBA). Se ha dedicado al estudio de temas de patrimonio cultural, museos y visitantes. Es responsable del área de 
investigación y coordinadora del taller de Estudios de Público en el Museo de Arte Popular José Hernández (GCBA).

Asimismo, se ha especializado en áreas de inmigración e interculturalidad, particularmente en la inmigración coreana en Argentina, sus procesos de construcción identitaria y las relaciones interétnicas. Actualmente es investigadora del Proyecto "Nuevos espacios de interculturalidad: coreanos y judíos en la ciudad de Buenos Aires", (PICT 2014) de la Agencia Nacional de Promoción científica y tecnológica. Ministerio de Ciencia y Técnica. Como especialista en temas de patrimonio cultural, interculturalidad y migración ha participado en diferentes proyectos de investigación, nacionales e internacionales, y es autora, de numerosos artículos sobre dichas temáticas. Entre ellos: Museos y visitantes. Ensayos sobre estudios de público en Argentina. ICOM Argentina. Conjuntamente con María Marta Reca (2017); "Reinterpretando el patrimonio artesanal: los estudios de visitantes en la gestión de museos" (2017); "La participación de jóvenes coreanos, argentino-coreanos, y argentinos en el campo cultural porteño" (2016); "El abordaje de la inmigración coreana en Argentina desde una perspectiva antropológica (2017); "Espacios urbanos interculturales en transformación: "Barrios coreanos en Buenos Aires" (2018) y "Sociabilidades e interculturalidad en el centro comercial de "Avellaneda" de la Ciudad de Buenos Aires" (2019).

\section{Introducción}

Desde la década de 1980, nuevas tendencias museológicas, abiertas a la pluralidad y a la construcción de espacios más inclusivos y participativos (ICOFOM-LAM, 2015), dan cuenta de un cambio paradigmático en el concepto de museo que incluye diferentes actores y problemáticas sociales. Estas instituciones son vistas ahora como foros de encuentro e intercambio, de socialización y negociación de identidades abiertos a la investigación y al surgimiento de nuevas ideas (Castilla, 2003, p. 2).

"Los museos son instancia para poder comprender reflexivamente los procesos culturales, múltiples, complejos, híbridos de los cuales son representativos los objetos que se muestran" (Cousillas, 2000, p. 22). En su concepción más contemporánea, se constituyen en un medio de comunicación colectiva y, como tal, en agentes de la democratización de la cultura. Pueden ser así el reflejo de la diversidad cultural de la sociedad, buscando asegurar la equidad de representación y atendiendo a las distintas características de los grupos culturales (Castilla, op.cit).También se configuran como lugares que, mediante la valorización de procesos y productos culturales, propician un enriquecimiento de la dimensión afectiva de las personas.

El Museo de Arte Popular José Hernández se inscribe en estas tendencias. Sus colecciones están constituidas principalmente por artesanías argentinas de los siglos XIX y XX entre las que se destacan fundamental pero no exclusivamente, la platería, el cuero, la cestería y los textiles, patrimonio que es interpretado como el resultado de un hacer, de un saber, de un proceso que entrelaza al productor cultural con su obra. Así se erige como el museo de las artesanías y de los artesanos, con una propuesta interactiva de comunicación de la cual 
estos últimos forman parte junto con el público dando lugar ya no sólo a la exhibición sino al aprendizaje y la participación comunitaria (Bialogorski, 2009).

En este marco se llevó a cabo en 2019 el proyecto Pertenencias. Narraciones textiles de mujeres migrantes en el Hemisferio Sur ${ }^{1}$, que integró propuestas textiles generadas en dos países: Nueva Zelanda y Argentina. Uno de sus objetivos fue mostrar problemáticas comunes de mujeres que migran de áreas rurales a centros urbanos, considerando la pérdida de su herencia cultural o, por el contrario, su (re)valorización y despliegue como parte de su identidad, tradición y su modalidad de inserción en el contexto receptor. Dicho proyecto incluyó entre sus ejes una exposición con piezas textiles realizadas por grupos de mujeres formados en los dos países mencionados, y por maestras artesanas de Argentina. Se realizaron a su vez, talleres tendientes a que las participantes pudiesen incorporarse al mundo laboral, como emprendedoras y facilitadoras de conocimientos ancestrales a través de su propio trabajo textil.

A partir de Pertenencias, nos pusimos en contacto con el grupo de artesanas que residen en Argentina y nos propusimos reflexionar acerca de conceptos tales como arte popular, saberes ancestrales, memoria, migración, identidad e hibridación cultural, a la luz de sus vivencias como tejedoras migrantes en la ciudad de Buenos Aires.

\section{Arte popular, saberes tradicionales, memoria e identidad}

La expresión Arte Popular ${ }^{2}$ no tiene un único significado ya que surge de la dinámica de diferentes campos de la gestión cultural en el siglo XX y varía según las tradiciones académicas, los países y los momentos históricos en los cuales se usan. Hace referencia a manifestaciones culturales que también se las nombra como artesanías o arte folk.

"Arte popular" incluye música, danzas, fiestas populares, creencias tanto como objetos con función utilitaria e intención artística, que se consideran expresión de una identidad regional, local o nacional. En Latinoamérica se habla de "artes populares" ya desde comienzo de la década de 1920. En Méjico, hacia 1922, se designa con este nombre a aquellas manifestaciones que "brotan espontáneamente del pueblo" y constituyen un elemento fundamental de la identidad nacional (Bialogorski, 2009).

En la Argentina, hasta fines del siglo XIX y principios del XX no se habla todavía de "arte popular", ni siquiera de "artesanía". En documentos oficiales se hace referencia a "industrias provinciales"; "producciones regionales" o a "manufacturas locales" que se distinguen así, de las manufacturas industriales.

Recién hacia 1937 se comienza a utilizar la expresión "artes populares" y se lo hace para designar a objetos con valores estéticos o formales más allá de la materia prima, que tienen en común haber sido producidos por los sectores populares de la sociedad. De hecho cuando se funda en 1948 en la ciudad de Buenos Aires, el Museo de Motivos Populares Argentinos "José Hernández" destinado a mostrar el "arte popular argentino", su colección la constituyen fundamentalmente objetos de platería criolla, cuero, platería y textiles.

En las primeras décadas del siglo XX, algunos de los bienes elaborados por sectores de la población indígena y criolla son interpretados por ciertos intelectuales como testimonios 
de un pasado que ligan a la identidad nacional. Se percibe a estos objetos elaborados con técnicas ancestrales, como supervivencias culturales que es imprescindible rescatar ya que habrán de extinguirse junto con sus productores.

Son saberes tradicionales, ancestrales, no importa si tienen origen remoto, que a veces se pierde en el tiempo, son modos de hacer cosas que también se transmiten de generación en generación y cuyo origen puede o no, ser rastreado. Si lo es, se las denomina tradiciones inventadas (Hobsbawm y Ranger, 1984) ${ }^{3}$.

Estos saberes se refieren al ámbito doméstico, familiar, y, podemos decir, también popular. Son transmitidos por la memoria colectiva, que es definida por Halbwachs (1968) como una memoria social, exterior al individuo, extendida en el tiempo, que guarda eventos acaecidos hace mucho. Es el envoltorio de las memorias que cada sujeto conserva y transmite a su manera.

Los individuos, a su vez, necesitan de esta memoria colectiva cuando quieren saber sobre situaciones de las cuales no fueron testigos y conforman el pasado de su grupo social o de referencia. La misma hace parte de la identidad, concepto discutido, en la llamada sociedad occidental contemporánea, aunque hay consenso de que se trata de una construcción social y no de una esencia, como se la consideraba en el siglo XIX y parte del siglo XX. No es una entidad estática sino un proceso de construcción de significado (Castells, 1996) que tiene por base un conjunto de atributos culturales interrelacionados, así como factores geográficos, biológicos e históricos y se nutre de la memoria y de la historia.

Las identidades según Hall (2003) se construyen dentro del discurso y no fuera de él, se producen a su vez en ámbitos históricos e institucionales en el interior de formaciones y prácticas discursivas mediante estrategias enunciativas específicas (Foucault, 1973). Se configuran a través de la diferencia, de la relación con el Otro (Hall, op. cit.); emergen en el juego de las modalidades del poder y son relacionales.

Según este autor, se trata de un atributo móvil, que se reforma y se transforma sincrónica y diacrónicamente. El sujeto post moderno, dice, tiene múltiples identidades que coexisten y se manifiestan de acuerdo a las circunstancias externas o a factores internos del propio individuo ya que éste integra una sociedad y en parte se encuentra moldeado por ella, al tiempo que por la historia y por su inconsciente. Se comporta de forma distinta dependiendo de las circunstancias y del grupo con el cual interactúa. Por momentos tenemos identidades diferentes, a veces hasta contradictorias: identidad familiar (somos hijos, padres, tíos, abuelos), identidad profesional (somos estudiantes, profesores); identidad de género, identidades legitimadoras (coordinador de, jefe de) y de resistencia (por ejemplo, feminista). Z. Bauman (2007) va más allá y habla de procesos de identificación pues, a lo largo de nuestra vida nos vamos identificando con diferentes causas, personas, ideas.

La identidad también implica un sentimiento de pertenencia a una comunidad imaginada (Anderson, 1991) cuyos miembros no se conocen pero que comparten historia y tradición. Y en este mundo contemporáneo mantener algún lazo, alguna identidad, sea étnica, local o regional parece ser esencial para que las personas no se pierdan en la vorágine de los millones de estímulos que día a día ofrecen, la tecnología y las industrias culturales. Las personas necesitan un ancla con el pasado, que les de seguridad, que les diga de dónde vienen.

La identidad tiene relación directa con las migraciones, una relación dialógica, una vez que el acto de migrar provoca nuevos contactos que llevan a nuevas identificaciones. 
Bauman (1998) afirma que actualmente todos estamos en movimiento. Si bien las sociedades humanas se caracterizan por la movilidad geográfica desde siempre, en los últimos dos siglos el fenómeno de mudarse de un lugar a otro -por diferentes motivos- se ha intensificado. Clifford (1997) agrega que no solamente los individuos, sino las propias culturas son itinerantes. Los productores culturales se desplazan por el mundo llevando sus manifestaciones, materiales o simbólicas. Lo anterior está intrínsecamente relacionado con la facilidad de trasladarse en el espacio, con la mejoría de los medios de transporte desde el fin de la Segunda Guerra, que no necesita ser fundamentada en este contexto.

A nivel global, vivimos en una sociedad cada vez más cosmopolita (Giddens, 2003), en la que habitan varias movilidades (Urry, 2000); donde los migrantes no son más considerados mitades en relación a una cultura sino dobles culturalmente (Featherstone, 1995) y se observa una "colonización inversa" en palabras del citado Giddens (p. 16) donde las culturas se influencian mutuamente.

En el caso de la sociedad mundial vemos a diario crecer las manifestaciones culturales del tercer mundo en el primero, y en el caso del continente americano acompañamos a las culturas aborígenes disputando lugar con las culturas hegemónicas, obligándonos a pensar en el cosmopolitismo como nuevo paradigma del siglo XXI ${ }^{4}$.

Todo lo anterior ha llevado a que haya producción artesanal cada vez más integrada en la que confluyen las vertientes de varias raíces históricas.

\section{Artesanas textiles migrantes en Buenos Aires: un proyecto en el MAP}

Argentina guarda aún en parte de su territorio, saberes y costumbres tradicionales que nos identifican y eso hace posible su conservación independientemente de intervenciones institucionales. A pesar de los grandes cambios provocados durante la segunda mitad del siglo XX por la industria cultural, el neoliberalismo, y la globalización, entre otros factores, hay todavía personas que, en su cotidiano, disfrutan de la continuidad con su historia, como puede ser, por ejemplo, tejiendo como lo hacían sus abuelas, con las técnicas y elementos que ellas utilizaban, uniendo así tradición y modernidad, saberes ancestrales y cultura urbana contemporánea.

El tejido que conocemos en nuestra cultura actual se puede rastrear hasta la prehistoria; hay vestigios datados en 7 mil años atrás dando cuenta del hilado y el cardado con husos. El telar surge en China en la edad antigua, al mismo tiempo que en América; se tejían prendas con hilos de alpaca y flores de algodón. Los países árabes aportaron las técnicas para teñir y las pinturas corporales dieron lugar a los decorados para los tejidos (Larrea Príncipe, 2007).

En Perú se han encontrado los tejidos más antiguos de las culturas sudamericanas y revelan que aproximadamente en el 4.000 a.C., se manufacturaban textiles en algodón, con técnicas como el anudado y el entrelazado. El primer diseño textil encontrado representaba un cóndor con las alas desplegadas, con una serpiente en el estómago. (Museo Nacional de Arqueología, Antropología e Historia del Perú $)^{5}$. 
En Argentina se han encontrado algunos vestigios de tejidos hechos con fibras vegetales, en regiones bien secas ${ }^{6}$. La seda del monte se hila desde la prehistoria y en el hilado se unen las tradiciones española, árabe e indígena. Los textiles tenían varios usos, entre ellos, eran moneda así declarada, por ejemplo, por el cabildo de Catamarca en 1684 (Eliçabe, 2014). Los diseños aparecerían a partir del año 1200 dC (López Campeny y Martel, 2014; Taboada, López Campeny y Angiorama, 2018).

En el Museo de Arte Popular José Hernández (MAP) se hace un trabajo constante de valorización, investigación, conservación, y exhibición de los saberes ancestrales materializados en las obras artesanales de su colección. En ella, los textiles ocupan un lugar fundamental. Así mismo se resalta el trabajo de los artesanos y se hace especial referencia a la mujer en el campo artesanal. Las protagonistas de la historia a las que hacemos referencia en este artículo son, precisamente, mujeres migrantes provenientes de dos provincias argentinas (Catamarca, y Entre Ríos) y de un país limítrofe, Paraguay, que residen en Buenos Aires y permanecen vinculadas simbólica y materialmente a su territorio mediante la artesanía textil. Tejen en telar criollo, de peine y de mesa. Emplean lana de llama, oveja, vicuña, alpaca, que traen, casi siempre, de su lugar de origen. También se dedican al crochet, trabajan con dos agujas, bordan y hacen ñandutí. En su producción advertimos técnicas ancestrales aplicadas tanto a diseños tradicionales como a modernos.

Ellas formaron parte, como dijimos al inicio, del proyecto Pertenencias llevado a cabo en el MAP y así fue que, en el ámbito del museo, nos vinculamos con estas artesanas y con sus relatos de vida, que entrelazan un pasado y un presente, un "aquí" y un "allá" y un conjunto de conocimientos tradicionales que se retroalimentan permanentemente en ese movimiento y que forman parte de la memoria de sus comunidades. A partir del análisis del material discursivo que obtuvimos mediante entrevistas pudimos acercarnos al significado que para cada una adquiría el hecho de tejer, conocer cuál es su vinculación con el lugar de origen, y también observar el proceso de hibridación por el que atraviesa su producción, fenómenos que reconfiguran, de alguna manera, la identidad de sus producciones, así como la de ellas mismas en cuanto artesanas tradicionales.

\section{Tejido: significados y práctica}

El tejer para nuestras entrevistadas adquiere distintos significados que se conectan con un sentimiento placentero y afectivo, con la memoria individual, el entorno y la historia familiar donde la figura de la mujer (la madre, la abuela, las tías), cobran una particular relevancia.

Por un lado, el tejer les produce bienestar, pasión. Para algunas personas es algo casi terapéutico:

"Me tranquiliza”, dice la artesana C. "Tejer para mí es relajante, me hace pensar, estar ahí, tranquila, [...] Me desestresa. [...]

"[tejer] Es todo, me abre la mente, tengo paz, tranquilidad, amor al tejido. Veo una lana y se me van las manos, veo un telar y se me van las manos. Tengo amor" (A.). 
“Todo el tiempo andábamos tejiendo. Fue así que empecé a tener el cariño, la pasión por el ñandutí" (C. L.).

Al hablar de esta acción van construyendo su memoria individual en la cual la familia y en particular la madre, ocupan un lugar central:

"Digamos que (el tejer) me conecta a tiempos con mi familia", dice C. y se emociona.

V. recuerda a su madre y hace suyas sus palabras: “[...] Mi mamá decía que en cada prenda que uno hace está uno mismo ahí [...] porque mientras vas tejiendo van todos los pensamientos, lo que uno sueña, ¡qué se yo! ¡Es hermoso!”

C. L. a su vez, reafirma: [...] "Tengo los mejores recuerdos de mi infancia y de mi adolescencia, [...] siempre nos sentábamos con mi mamá a tomar lo que nosotros decimos tereré, el mate frío para ustedes (los argentinos). Y tejíamos".

O como grafica Antonia enlazando el tejido con el recuerdo de su madre y un momento especial del día que aún en el presente es significativo para ella:

"Los recuerdos lindos que tengo es tejer, es ver a mi mamá a la tarde, sentada. Lo más bello que tengo lo que me quedó es urdir a la tarde, tejer siempre a la tarde. No sé por qué pero cuando cae el sol me pongo a urdir y tejo, me parece que tengo más luces para eso".

También aparece la figura de la abuela traspasando su conocimiento en las labores relacionadas al tejido y al bordado, desde la época en que vivían en el campo:

"Yo había empezado a la edad de 8 años [...], chiquitita [a hacer ñandutí]. Yo siempre veía a mi abuelita [...] tejiendo" (C. R.).

"Desde muy jovencita me puse a tejer, dice C. [...] A mí me crió mi abuela, [...] con ella, con mis tías, me enseñaron a tejer y a bordar".

A. nos cuenta "recuerdo que mi abuela me llevaba a esquilar, que lo más bello era esquilar en ese tiempo [...] Ella iba al campo, esquilaba, traía la lana, hacía todo el proceso (de teñido) con las raíces naturales. [...] Es la que me impulsó a esquilar, a hilar, a teñir”.

Para C., quien también aprendió a tejer con su abuela, su ausencia se vuelve tan potente que la lleva a afirmar, con las lágrimas en sus ojos:

"Hace 5 años que no vuelvo [a mi país]. Desde que falleció mi abuela no volví".

Con respecto al vínculo con el lugar de origen advertimos en todos los casos que el regreso temporal al mismo se hace efectivo con cierta periodicidad. En un movimiento circular A. que trajo a la ciudad su saber textil, vuelve a su pueblo y transmite lo que, a su vez, aprendió en ella:

"[...] en un tiempito que me queda me voy a mi pueblito, que mi pueblo es el que me brindó, me dio estas raíces. Todo lo que aprendo acá lo voy a volcar en mi gente”.

También se vuelve al terruño simplemente para descansar, o pasar las vacaciones. Esto estimula los recuerdos y lleva a revivir momentos de un pasado, sea reciente o un poco más lejano.

"Lo más hermoso para mí es Belén. Las vacaciones me las paso todo el tiempo allá. Cuando empieza la escuela mi hijo ya venimos. A fines de diciembre ya me voy. Cuando mi mamá estaba viva íbamos 4 o 5 veces al año" (V.).

"Siempre vuelvo a Catamarca en mis vacaciones, donde pasé mi niñez y donde toda la familia hilaba, tejía y hacía intercambio por una bolsa de harina, por una bolsa de azúcar, era así” (R.). 
También aprovechan sus viajes para traer artesanías textiles o materia prima para comercializar en Buenos Aires:

"Generalmente voy una vez al año y aprovecho ese tiempo que voy para traer algunas cositas para vender" (C. R.).

"Yo voy directamente (a mi pueblo) pero a buscar hilado para hacer (en Buenos Aires)" (V.). En sus relatos, las artesanas evocan de su lugar de origen los olores, el paisaje: "De Paraguay extraño mucho el campo, sí, no hay otra cosa que extrañe que el campo" (C.).

El tejer las une, las transporta a sus pagos y hasta les hace olvidar lo lejos que se encuentran: "Cuando tejo me olvido que estoy acá" (en Buenos Aires) y sienten la necesidad de volver: "Cuando estoy acá, me quiero ir a Belén" (V.).

Como se puede observar todos estos testimonios están atravesados por la emoción que, como dice Le Bréton (2012) es a la vez interpretación, expresión, significación que se diferencia en su intensidad de acuerdo a la singularidad de cada persona pero que, afirma, posee un carácter socialmente construido (Ibid, p. 68).

A partir de la actividad textil se genera una red de significados que une a las artesanas con sus comunidades. Según el mencionado autor, para que una emoción sea sentida, percibida y expresada por el individuo, debe pertenecer a una u otra forma del repertorio cultural del grupo al que pertenece. Cada estado afectivo es para el sujeto, parte de un conjunto de significados y de valores de los que no puede desprenderse sin perder su sentido. Una cultura afectiva forma una trama en la que cada emoción está colocada en perspectiva dentro de un conjunto (Ibid, p. 72). [La emoción] "se cuela en el simbolismo social y los rituales vigentes. No es una naturaleza descriptible sin contexto ni independiente del actor" (Ibid, p. 75).

El tejer es un saber ancestral y se transmite de generación en generación. Como dice C. R. "con mi mamá y mi hermana hacíamos en familia, en grupo, el vestido porque también tenemos una creencia de que [...] venimos aprendiendo de nuestros antepasados [...]". Algunas personas aprenden desde muy chicas:

“Esto que sé es gracias a mi abuela que ya no está más, pero me dejó este aprendizaje tan lindo. Cuando era chica ella me decía "Aprendé, hija, que alguna vez te va a servir" y la verdad es que me sirvió y para mucho" (A.).

Otras pasan a interesarse en la juventud:

"Yo aprendí de [mi mamá] a tejer, a hacer las guardas [... "Recién aprendí de ella a los 17, 18 años ya estando acá en Buenos Aires" (V.).

Hoy día ese conocimiento ancestral se transmite en la ciudad a través de talleres y en instituciones educativas, tal el caso de A. que enseña en colegios así como en su casa donde no sólo transmite las técnicas sino todo el proceso del tejido, dando cuenta de su valor. Ella explica, "tengo telares criollos, tengo telares de mesa, enseño a hilar, enseño a que las alumnas sepan lo que es el material que uno emplea para hacer una obra, una muestra, un trabajo porque acá uno va y lo compra en la tienda, en la lanera. En cambio, si ellas saben de dónde viene y todo el trabajo que lleva esquilar la lana, que hay que abrirla, sacarle la basurita, hilarla, torcerla, teñirla, ven que tiene un trabajo". 


\section{Inserción en la sociedad receptora}

El proceso de inserción económico-social en Buenos Aires ha sido diferente para cada una de las entrevistadas, por diversas razones. Por ejemplo C. no había traído sus instrumentos de trabajo cuando llegó y su actividad en un principio, no estuvo ligada a la artesanía:

“[...] cuando llegué acá no traje los materiales necesarios así que no pude trabajar con el ñandutí [...] los materiales que necesitamos para hacer el ñandutí es el bastidor que se hace de madera depende de la medida, telas que es el lienzo, los hilos y la aguja”.

Nos aclara que, posteriormente, volvió a Paraguay y decidió traer sus implementos de trabajo, así como materia prima e incluso productos terminados para comercializar.

C. R. dice "[...] el tejer el ñandutí [...], me hizo cambiar la vida porque cuando vine de Paraguay traje un montón [...] y vi que era una artesanía muy valiosa, muy apreciada por otra gente que no son del mismo país de donde es originario el ñandutí, así que eso me impulsó a viajar cada tanto a Paraguay y traer [...] para vender en Argentina”.

V. a su vez tuvo una muy buena inserción en la ciudad, con un espacio en la Feria de Mataderos, que desde el punto de vista logístico es privilegiado ya que se trata de una feria, ámbito de cultura tradicional gauchesca, que funciona todos los domingos en el barrio del mismo nombre.

Esta artesana teje con lana de llama o de alpaca, y a través de su relato nos interiorizamos de cuestiones técnicas, económicas y valorativas del hacer artesano. "La lana tiene que ser virgen para que agarre la tinta” -nos dice-, agregando que aquí (Buenos Aires) solo se vende lana mezclada. Y a veces tiene que esperar que la lana llegue del norte, lo que aumenta más aún el tiempo que lleva tejer un poncho, que es, en promedio, un mes. Estos tiempos y la dedicación que insume cada prenda encarece su precio, lo que suele ser cuestionado por los potenciales compradores que, según V. no advierten el valor del trabajo artesanal. Las artesanas buscan insertarse en el mercado, vender su producción, generar sus propios emprendimientos, y para lograr ese objetivo se tienen que adecuar en mayor o menor medida a las exigencias de sus clientes que están, casi inevitablemente permeadas por los gustos inducidos por la industria.

V. elabora ponchos, frazadas y ruanas, prendas tradicionales y modernas. Crea piezas con su saber ancestral pero al gusto de los nuevos consumidores. El poncho, originalmente es de fibras naturales, sin tintes industriales. No obstante, ella hace ponchos de colores, teñidos con anilinas, para atender la demanda del mercado urbano.

Lo mismo ocurre con C. R., quien utiliza el ñandutí como aplique en remeras y carteras. Podríamos decir que este proceso constituye una hibridación cultural, concepto desarrollado por García Canclini (1990) a propósito de las culturas de los países latinoamericanos, por el cual se une tradición y modernidad y es el paradigma de las culturas migratorias. Se adecua muy bien a lo que observamos en nuestro universo de investigación. Este fenómeno surge del contacto entre dos o más culturas que tienen una existencia separada y en determinado momento se unen para formar una nueva dinámica. La hibridación cultural no substituye una cultura con otra; reformula las costumbres, conservando los rastros de cada una de las anteriormente existentes. Este proceso, que comienza con la modernidad, en América Latina ha sido una estrategia de adaptación que se ha mostrado exitosa. Sería una resistencia profunda de la cultura ancestral, algo que podríamos definir 
como una cultura residual, de acuerdo con el concepto de Williams $(1988)^{7}$ que se viene manifestando cada vez con más énfasis a medida que avanza el siglo XXI ${ }^{8}$.

\section{Consideraciones finales}

Las artesanas que entrevistamos son mujeres migrantes del norte argentino y del exterior, que tejen su saber ancestral en el medio urbano porteño.

Sus tejidos y bordados, atravesados siempre por la emoción, se convirtieron en algunos casos en un medio de vida con sus vicisitudes coyunturales, y en otros son mera pasión y continuidad con sus raíces. En esas tramas van sus memorias de la infancia, del terruño, de su familia y de su comunidad de origen.

El estar en dos mundos constituye una situación privilegiada para su creación, va reconfigurando sus identidades y da una impronta a sus obras, que son producto de su cultura híbrida.

Haber participado del proyecto Pertenencias permitió a las artesanas diversificar sus técnicas así como inspirarse para generar emprendimientos propios. Las colocó además, en contacto e interacción con el patrimonio textil del MAP, con sus referentes y con el público visitante que pudo conocerlas y apreciar su obra. Para la institución significó poner una vez más, en valor a los/as productores/as y producciones culturales, en este caso, textiles, dando continuidad a proyectos de extensión comunitaria que enfatizan el rol social que deben tener los museos contemporáneos.

\section{Notas}

1. Pertenencias fue uno de los proyectos ganadores de Maleta Abierta / Iber-rutas.org, auspiciado con fondos de la Secretaría General Iberoamericana en 2019. Fue dirigido por Ximena Eliçabe y Marcia Veneziani e integró propuestas textiles generadas en Nueva Zelanda y Argentina.

2. El concepto de arte popular aparece mencionado en 1927 en la revista Mouseion, publicada en Francia por la Oficina Internacional de Museos.

3. Por tradición entendemos, a partir de Hobsbawm y Ranger (op. cit.) el conjunto de prácticas siempre iguales gobernadas por reglas aceptadas tácitamente, de naturaleza ritual o simbólica cuyo origen se pierde en el pasado.

4. Para una aproximación más amplia al concepto de cosmopolitismo, ver Beck, U. (2002). “The Cosmopolitan Society \& Its Enemies". Theory Culture \& Society 19(1-2): 17-44.

5. Ver Museo Nacional de Arqueología, Antropología e Historia del Perú. Disponible en: https://mnaahp.cultura.pe/colecciones/textiles-0

6. López Campeny y Martel (2014, p. 28) refieren a registros de entre 650 y $1060 \mathrm{dc}$ en el Pucará de Tilcara y un registro de 1180 dC en Calingasta, San Juan. 
7. No se refiere a algo que ya no existe más sino a algo que se formó en el pasado pero tiene vigencia en el presente.

8. A propósito de este tema ver López Hernández (2006).

\section{Referencias}

Anderson, B. (1991). Imagined Communities: Reflections on the Origin and Spread of Nationalism. London: Verso.

Bauman, Z. (1998). La globalización. Consecuencias humanas. Mexico-Argentina: Fondo de Cultura Económica (FCE).

Beck, U. (2002). “The Cosmopolitan Society \& its Enemies." Theory Culture \&Society 19(1-2): 17-44.

Bialogorski, M. (2009). “Campo semiótico y campo artesanal: el juego de las transformaciones y los bordes” Acta Semiotica Fennica (ASF) XXXIV. Eero Tarasti, Ed. Helsinki,Finlandia, pp. 177-184.

Castells, M. (1996). El poder de la identidad. Madrid: Ed. Alianza.

Castilla, A. (2003): “Una política cultural para los Museos en Argentina” - Documento de discusión para ser debatido con las Secretarías de Cultura de las provincias y el Gobierno de la Ciudad de Buenos Aires, museos de todas las especialidades, entidades sin fines de lucro con interés en los museos, artistas, galeristas de arte, científicos, historiadores, coleccionistas e interesados en general. Disponible en www.cultura.gob.ar

Cousillas, A. (2000). "La percepción-interpretación del patrimonio cultural en el ámbito de los museos". En: Revista Temas de Patrimonio Nro.1 - Comisión de Preservación del Patrimonio Histórico Cultural de la Ciudad de Buenos Aires - Secretaria de Cultura Gobierno de la Ciudad de Buenos Aires.

Eliçabe, X. (2014). Arte textil y tradición en la Provincia de Catamarca, noroeste argentino. Cuaderno 47. Centro de Estudios en Diseño y Comunicación. pp 107-115.

Foucault, M. (1973). La arqueología del saber. Méjico: Siglo XXI.

Featherstone, M. (1995). Global Culture: nationalism, globalization and modernity. London: Sage.

Giddens, A. (2003). Runaway World. How globalization is reshaping our lives. New York: Routledge.

Garcia Canclini, N. (1990). Culturas Híbridas. Estrategias para entrar y salir de la modernidad. México: Grijalbo.

Halbwachs, M. (1968). La memoire collective. Paris: PressesUniversitaires de France.

Hall, S. (2001). A identidade cultural napósmodernidade. Rio de Janeiro: DP\&A.

Hobsbawm, E. y Ranger, T. (1984). A invenção das Tradições. R. J.: Paz e Terra.

ICOFOM-LAM (2015). Actas del XXIII Icofom-Lam, Panamá. 18, 19 y 20 de noviembre. Disponible en: http://network.icom.museum/fileadmin/user_upload/minisites/icofom/ pdf/ACTAS_ICOFOM_LAM_2015_PANAMA.pdf 
Larrea Príncipe, I. (2007). El significado de la creación de tejidos en la obra de mujeres artistas. Tesis doctoral dirigida por Elena Mandizabal Egialde. Facultad de Bellas Artes. Universidad del País Vasco.

Le Breton, D. (2012). "Por una antropología de las emociones" en: Revista Latinoamericana de Estudios sobre Cuerpos, Emociones y Sociedad - RELACES. 10 (4). Córdoba. Disponible en: http://www.relaces.com.ar/index.php/relaces/article/view/208

López Campeny, S. M. L. y Martel, A. R. (2014). La Vestimenta del Poder. Comparando Los Registros Textil y Rupestre en el Noroeste de Argentina (siglos XIII a XV), Relaciones de la Sociedad Argentina de Antropología XXXIX (1), enero-junio. pp. 21-55.

López Hernández, M. (2006). Creatividad invisible. Mujeres y arte popular en América Latina y el Caribe. La Colmena, núm. 49, pp. 108-112. Universidad Autónoma del Estado de México. Toluca.

Taboada, C.; López Campeny, S. y Angiorama, C. (2018). Una placa de metal y un tejido de algodón: implicancias en relación a procesos locales, incaicos y coloniales en la llanura de Santiago del Estero (Argentina). Arqueología y Antropología Surandinas, No 59, pp. 121-154 Urry, J.(2000). "Sociology beyond societies. Mobilities for the twenty-first century". London: Routledge.

Williams, R. (1988). Marxismo y literatura. Barcelona: Península.

Museo Nacional de Arqueología, Antropología e Historia del Perú. Disponible en: https:// mnaahp.cultura.pe/colecciones/textiles-0

\begin{abstract}
Grounded on a project developed at José Hernández Museum of Popular Art (GCBA) with women textile artisans from Argentina and Paraguay, this article deliberates about folk art, ancestral knowledge, memory, migration, identity and cultural hybridization, concerning their experiences as migrant weavers in Buenos Aires city. The aforementioned concepts are defined, reference is made to some respondents life history and to the meaning they give to the act of weaving. In terms of their products as well as the way they are made and also the attachment to their homeland to which they often return, they are carriers of traditional knowledge, as well as a hybrid culture. Entering and leaving modernity, they integrate into the city through abilities they inherited from their elder folks. Being in two worlds reconfigures their identities and gives a cultural imprint to their creations.
\end{abstract}

Keywords: textile artisans - hybrid cultures - migration - folk art - identity - memory.

Resumo: A partir de um projeto desenvolvido no Museu de Arte Popular José Hernández (GCBA) com tecelãs de Argentina e Paraguai, objetivamos refletir sobre conceitos como arte popular, saberes ancestrais, memória, migração, identidade e hibridismo cultural, sob a luz do que vivenciam, enquanto tecelãs, as migrantes na cidade de Buenos Aires. São definidos os conceitos antes mencionados, se relata o caminho transitado por algumas das entrevistadas o que para elas significa o ato de produzir o tecido. Elas são portadoras 
de conhecimentos tradicionais, assim como de uma cultura híbrida, tanto naquilo que produzem quanto na forma em que o fazem e no apego à sua terra natal, para ondem retornam com frequência. Entrando e saindo da modernidade, se integram na cidade por meio do seu saber, herdado dos mais velhos. Estar em dois mundos acaba por reconfigurar suas identidades e outorga um selo às suas criações.

Palavras chave: tecelãs - culturas híbridas - migração - arte popular - identidade - memória.

[Las traducciones de los abstracts fueron supervisadas por el autor de cada artículo] 